\title{
Mothers' Attitude Towards Childhood Diarrhea Management and Prevention in Under Five Children in Fenote Selam Town, West Gojjam, Amhara, Northwest Ethiopia
}

\author{
Desalegne Amare ${ }^{1, *}$, Getachew Mullu² \\ ${ }^{1}$ Nursing Department, Medicine and Health Science Collage, Debre Markos University, Debre Markos, Ethiopia \\ ${ }^{2}$ Midwifery Department, Medicine and Health Science Collage, Debre Markos University, Debre Markos, Ethiopi
}

Email address

desa2001@yahoo.com (D. Amare),gechm2005@gmail.com (G. Mullu)

\section{To cite this article:}

Desalegne Amare, Getachew Mullu. Mothers' Attitude Towards Childhood Diarrhea Management and Prevention in Under Five Children in Fenote Selam Town, West Gojjam, Amhara, Northwest Ethiopia. Science Journal of Public Health. Vol. 3, No. 3, 2015 , pp. $398-403$.

doi: $10.11648 /$ j.sjph.20150303.25

\begin{abstract}
Introduction: Global deaths of children aged less than five years from diarrhea have been estimated, resulting in about 800000 fatalities worldwide annually, most occurring in sub-Saharan Africa and south Asia. More than $80 \%$ of these deaths occur in Asia and Africa (46\% in Africa alone). Objective: The aim of this study was to assess attitude of mothers towards diarrhea management and prevention in under five children, in Fenote Selam Town, West Gojjam Zone, Amhara, Northwest Ethiopia, 2014. Methods: Community based Cross-sectional study was conducted from April-May 2014. The sample size was 846. Multi-stage sampling technique was employed to select sampling kebeles. Simple random sampling technique was used to select study units. Pretest was done in none sampling kebeles. Data were entered into Epi-info (version 3.5.1) statistical software package and then exported to SPSS software package version 16.0 for further analysis. Results: A total of 830 mothers were participated in the study. Overall, 416(50.1\%) of mothers had favorable attitude. Of these, 337 (40.6\%) of mothers had favorable attitude towards ORS usage and 192(23.1\%) of mothers had favorable attitude towards immunization to prevent diarrhea. Conclusion: Overall, half of mothers of the Fenote Selam community had unfavorable attitude towards diarrhea management and prevention.
\end{abstract}

Keywords: Attitude, Prevention, ORS, Under Five Children, Mother, Diarrhea, Management

\section{Introduction}

Global deaths of under five children from diarrhea have been estimated 800000 [1]. More than $80 \%$ of these deaths occur in South Asia and Africa (46\% in Africa alone) [2]. Although diarrheal mortality remains high, it is decreasing by $4 \%$ per year [1], and incidence is declining more modestly [3]. To guide these effort, robust data characterize the burden, risk factors, microbiological a etiology, squeal and case fatality of most life-threatening and disabling episodes are essential; heretofore, such data have been scarce in regions with the highest child mortality[4].

In Sub-Saharan Africa primary caregivers display poor perception about the signs of dehydration, dysentery and management of diarrhea [5]. The attitude of parents and caretakers towards the disease management vary with their perception about its seriousness especially on young children and health care-seeking practices of the primary caretakers of children $<5$ years of age [6].

Data from EDHS showed that an increase in mothers' health seeking behavior for children with diarrhea over the past decade; it was $13 \%$ in 2000 to $22 \%$ in 2005 and $32 \%$ in 2011. However, almost one child in every two (49\%) were offered less fluid than usual or were given no fluids at all; $28 \%$ were offered somewhat less, $13 \%$ were offered much less, and $7 \%$ of children were offered no fluids at all. Only $10 \%$ of children with diarrhea were given increased liquids and continued feeding as recommended, while $25 \%$ of children with diarrhea continued to be fed and given ORT[7].

The purpose of this study was to assess attitude of mothers towards diarrhea management and prevalence in under five children, in Fenote Selam Town, West Gojjam Zone, Amhara, 
Northwest Ethiopia.

\section{Methods and Materials}

\subsection{Study Setting}

The study was conducted in Fenote Selam Town which is $378 \mathrm{~km}$ from the capital City of Ethiopia, Addis Ababa. In the town administration, there are 5 kebeles: three in urban and two in the rural. The study was conducted from April to May, 2014.

\subsection{Study Design}

A community based cross- sectional study was conducted.

\subsection{Source and Study Population}

All mothers who had under five children and live in Fenote Selam Town were the source populations. All mothers in reproductive age groups who had under five children in selected kebeles were the study population.

\subsection{Inclusion and Exclusion Criteria}

All mothers in the reproductive age group who had under five children were included in the study. Mentally ill, seriously ill, mothers who had hearing and speaking difficulties were excluded from the study.

\subsection{Sample Size Determination}

To determine the sample size, single population proportion formula was used. Using assumption of 95\% confidence interval with $5 \%$ sampling error, the sample size calculation was:

$$
\begin{gathered}
n=\frac{z^{2} * P(1-P)}{d^{2}} \\
\frac{(1.96)^{2}(0.5 * 0.5)}{(0.05)^{2}}=384
\end{gathered}
$$

By using design effect it was multiply by 2 $384 * 2=768$

$10 \%$ of none response rate $\mathrm{n}=846$

\subsection{Sampling Technique and Procedure}

Fenote Selam Town was selected purposively since the study area has densely population. Multistage sampling technique was used to select sampling kebeles. Both urban and rural kebeles were included in the study. Accordingly, kebele 01 from urban and kebele 04 from rural were selected randomly. Simple random sampling technique was used to select the study units.

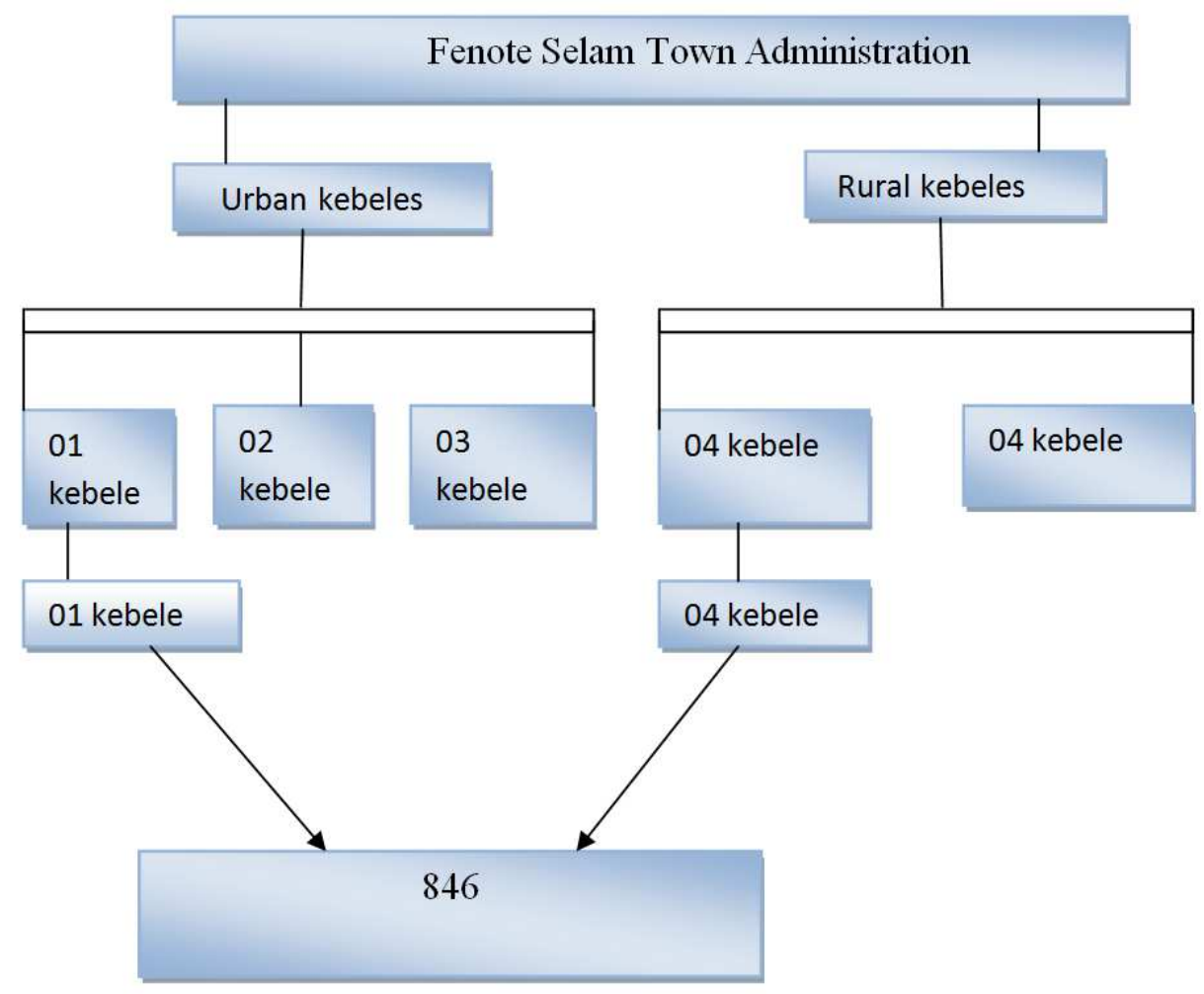

Figure 1. Schematic presentation of sampling procedures.

\subsection{Data Collection Instrument}

Interview questionnaires were adapted and modified from related literatures. Data were collected by trained nurses. The questionnaires were translated into the local language (Amharic) for easy understanding by the respondents. 


\subsection{Data Quality Assurance}

Orientation was given for supervisors and data collector nurses concerning the purpose of the study and ethical considerations. Guidelines were given for data collector nurses and supervisors. The supervisors were monitoring the data collection process. Pretest was done on 5\% of samples from non-sampled kebeles, and necessary correction was made on the clarity of language, sequencing $\&$ workability of questioners.

\subsection{Data Processing and Analysis}

Each completed questionnaires were coded on prearranged coding sheet to minimize errors. Data were checked again for its completeness. The data were entered into Epiinfo (version 3.5.1) statistical software package and then exported to SPSS software package (version 16.0) for further analysis. Ten percent of the responses were randomly selected and checked for the consistency of the data entry. Data cleaning process was done by running simple frequency for its consistency.

\subsection{Ethical Consideration}

Ethical clearance and approval was obtained from DMU, College of Medicine and Health Sciences Ethical Review Committee (IRBs). The Ethical Review Committee wrote official letter to Fenote Selam Town Administration, and then it was communicate at each level. Written information was obtained from study participants. Confidentiality of information was assured.

\section{Results}

Socio demographic characteristics of study participants: A total of 830 participants were participated. The response rate of the study was $98.1 \%$. Of the total participants, $264(31.8 \%)$ were in the age range of $36-45$ years old. About $461(55.5 \%)$ of participants were married. most of the study participants were Amhara ethnicity (99.6\%). About 736(88.7\%) of study participants were Orthodox (Table 1).

About 372(44.8\%) mothers strongly agreed that exclusive breast feeding is important to prevent diarrhea while 11(1.3\%) mothers strongly disagreed. $337(40.6 \%)$ of the mothers strongly agreed that ORS is a fluid which replace fluid and electrolyte loss by diarrhea. 192(23.1\%) of mothers believed that immunized children are diarrhea preventable than unimmunized children (Table 2).

Table 1. Socio demographic characteristics of study participants in Fenote Selam Town Amhara, Northwest Ethiopia, 2014.

\begin{tabular}{|c|c|c|}
\hline Variables & Category & Frequency, N (\%) \\
\hline \multirow{4}{*}{ Age } & $15-24$ & $153(18.4)$ \\
\hline & $25-35$ & $244(29.4)$ \\
\hline & $36-45$ & $264(31.8)$ \\
\hline & $>45$ & $169(20.4)$ \\
\hline \multirow{4}{*}{ Marital status } & Married & $461(55.5)$ \\
\hline & Single & $101(12.2)$ \\
\hline & Divorce & $119(14.3)$ \\
\hline & Widowed & $149(18)$ \\
\hline \multirow{3}{*}{ Ethnicity } & Amhara & $827(99.6)$ \\
\hline & Oremo & $1(0.1)$ \\
\hline & Tigraye & $2(0.2)$ \\
\hline \multirow{3}{*}{ Religion } & Orthodox & $737(88.8)$ \\
\hline & Muslim & $68(8.2)$ \\
\hline & Protestant & $25(3)$ \\
\hline \multirow{5}{*}{ Educational status } & Illiterate & $298(35.9)$ \\
\hline & Elementary school & $220(26.5)$ \\
\hline & High school & $150(18.1)$ \\
\hline & Collage & $126(15.2)$ \\
\hline & University & $36(4.3)$ \\
\hline \multirow{5}{*}{ Occupational status } & Government employee & $206(24.8)$ \\
\hline & Private & $145(17.5)$ \\
\hline & Housewife & $254(30.6)$ \\
\hline & Merchant & $107(12.9)$ \\
\hline & Laborer & $118(14.2)$ \\
\hline \multirow{7}{*}{ Monthly income } & $151-651$ & $222(26.7)$ \\
\hline & $652-1400$ & $233(28.1)$ \\
\hline & $1401-2350$ & $154(18.6)$ \\
\hline & $2351-3550$ & $52(6.3)$ \\
\hline & $3551-5000$ & $15(1.8)$ \\
\hline & $>5000$ & $5(0.6)$ \\
\hline & No source of income & $149(18)$ \\
\hline \multirow{3}{*}{ Number of children } & $1-2$ & $388(46.7)$ \\
\hline & $3-4$ & $274(33)$ \\
\hline & $>4$ & $168(20.2)$ \\
\hline Total & & 830 \\
\hline
\end{tabular}

Table 2. Attitude of mothers towards diarrhea management in under five children in Fenote Selam, Amhara, Northwest Ethiopia, 2014.

\begin{tabular}{lllll}
\hline Variables & $\begin{array}{l}\text { Strongly agree } \\
\mathbf{N}(\mathbf{\%})\end{array}$ & $\begin{array}{l}\text { Agree } \\
\mathbf{N}(\%)\end{array}$ & $\begin{array}{l}\text { Disagree } \\
\mathbf{N}(\%\end{array}$ & $\begin{array}{l}\text { Strongly disagree } \\
\mathbf{N}(\%)\end{array}$ \\
\hline Exclusive breast feeding can prevent diarrhea. & $372(44.8)$ & $297(35.8)$ & $150(18.1)$ & $11(1.3)$ \\
ORS and other fluid replace fluid loss and electrolyte imbalance & $337(40.6)$ & $376(45.3)$ & $111(13.4)$ & $6(0.7)$ \\
vaccination can prevent diarrheal disease & $367(44.2)$ & $311(37.5)$ & $139(16.7)$ & $13(1.6)$ \\
complementary feeding before 6 months is important for a child health & $192(23.1)$ & $211(25.4)$ & $334(40.2)$ & $93(11.2)$ \\
\hline
\end{tabular}

Mean value of the attitude questions was $547.4(66 \%)$. Based on the mean value, $416(50.1 \%)$ of the mothers had favorable attitude while 414(49.9\%) had unfavorable attitude (Table 3). 
Table 3. Mean value and level attitude of mothers towards diarrhea management in under five children.

\begin{tabular}{llll}
\hline $\begin{array}{l}\text { Dependent } \\
\text { variables }\end{array}$ & Mean value & & Level of attitude \\
\cline { 2 - 4 } & Respondents answered correctly & Respondents answered incorrectly & Favorable attitude \\
\hline Attitude & $547.4(66 \%)$ & $282.8(34 \%)$ & Unfavorable attitude \\
\hline
\end{tabular}

In multivariate logistic analysis, single, divorced and widowed marital status of the mothers were independently associated with unfavorable attitude (AOR (2.541, 3.596 $\& 1.625)$ and $95 \%$ CI $(1.564,4.130),(2.238,5.778)$ and $(1.047,2.522)$ respectively). Educational status of mothers were independently associated with unfavorable attitude (cannot read and write and elementary education which were $\mathrm{AOR}=2.979,95 \% \mathrm{CI}(1.135,7.816)$ and $\mathrm{AOR}=2.681,95 \%$ CI $(1.019,7.049))$, respectively. Housewife mothers were strongly associated with unfavorable attitude (AOR 2.574, 95\% CI (1.434, 4.623) (Table 4).

Table 4. Bivarate and multivariate logistic analysis of mothers' attitude towards diarrhea management in under five children Fenote Selam, Amhara, Northwest Ethiopia, 2014.

\begin{tabular}{|c|c|c|c|c|c|c|}
\hline \multirow{2}{*}{ Variables } & \multicolumn{2}{|l|}{ Attitude } & \multirow{2}{*}{ COR* $(95 \% C I)$} & \multirow{2}{*}{ P-value } & \multirow{2}{*}{$\operatorname{AOR}^{* *}(95 \% \mathrm{CI})$} & \multirow{2}{*}{ P-value } \\
\hline & Unfavorable attitude & Favorable attitude & & & & \\
\hline \multicolumn{7}{|l|}{ Age } \\
\hline $15-24$ & $69(45.1 \%)$ & $84(54.9 \%)$ & 1.00 & --- & 1.00 & --- \\
\hline $25-35$ & $107(43.9 \%)$ & $137(56.1 \%)$ & $0.951(0.633,1.428)$ & 0.808 & $1.018(0.559,1.853)$ & 0.954 \\
\hline $36-45$ & $138(52.3 \%)$ & $126(47.7 \%)$ & $1.333(0.894,1.988)$ & 0.158 & $0.943(0.564,1.575)$ & 0.822 \\
\hline$>45$ & $100(59.2 \%)$ & $69(40.8 \%)$ & $1.764(1.134,2.745)^{*}$ & 0.012 & $1.088(0.687,1.724)$ & 0.720 \\
\hline \multicolumn{7}{|l|}{ Marital status } \\
\hline Single & $59(58.4 \%)$ & $42(41.6 \%)$ & $2.254(1.455,3.493)^{*}$ & 0.000 & $2.541(1.564,4.130)^{* *}$ & 0.000 \\
\hline Divorced & $85(71.4 \%)$ & $34(28.6 \%)$ & $4.011(2.584,6.227)^{*}$ & 0.000 & $3.596(2.238,5.778)^{* *}$ & 0.000 \\
\hline Widowed & $93(62.4 \%)$ & $56(37.6 \%)$ & $2.665(1.820,3.900)^{*}$ & 0.000 & $1.625(1.047,2.522)^{* *}$ & 0.030 \\
\hline \multicolumn{7}{|l|}{ Educational status } \\
\hline Illiterate & $193(64.8 \%)$ & $105(35.2 \%)$ & $5.514(2.500,12.162)$ & 0.000 & $2.979(1.135,7.816)^{* *}$ & 0.027 \\
\hline Elementary school & $120(54.5 \%)$ & $100(45.5 \%)$ & $3.600(1.618,8.010)$ & 0.002 & $2.681(1.019,7.049)^{* *}$ & 0.046 \\
\hline High school & $58(38.7 \%)$ & $92(61.3 \%)$ & $1.891(0.831,4.306)$ & 0.129 & $1.388(0.531, .531)$ & 0.504 \\
\hline \multicolumn{7}{|l|}{ Occupational status } \\
\hline Government & $60(29.1 \%)$ & $146(70.9 \%)$ & 1.00 & ---- & 1.00 & \\
\hline Private employee & $81(55.9 \%)$ & $64(44.1 \%)$ & $3.080(1.974,4.805)^{*}$ & 0.000 & $1.308(0.700,2.444)$ & 0.400 \\
\hline House wife & $169(66.5 \%)$ & $85(33.5 \%)$ & $4.838(3.250,7.202)^{*}$ & 0.000 & $2.574(1.434,4.623)^{* *}$ & 0.002 \\
\hline Merchant & $43(40.2 \%)$ & $64(59.8 \%)$ & $1.635(1.002,2.668)^{*}$ & 0.049 & $1.014(0.528,1.947)$ & 0.966 \\
\hline Daily worker & $61(51.7 \%)$ & $57(48.3 \%)$ & $2.604(1.628,4.166)^{*}$ & 0.000 & $0.902(0.462,1.762)$ & 0.763 \\
\hline
\end{tabular}

Foot note: $*=$ significant for $\mathrm{COR}, * *=$ significant at AOR

\section{Discussion}

This study showed that the mean value of attitude questioners was $66 \%$ and $50.1 \%$ of the mothers had favorable attitude for diarrhea management.

This study showed that $80.6 \%$ of mothers had favorable attitude towards exclusive breast feeding, and $32.9 \%$ of mothers had favorable attitude towards avoiding mixed breast feeding. $81.7 \%$ of mothers had favorable attitude that vaccination is important to prevent diarrhea. Other similar study indicated that the largest proportion of the respondents had favorable attitude towards diarrhea management[8] . About two-third of the mother disagreed with the statement that vaccine might be harmful for health and $97 \%$ of the study participants had favorable attitude toward diarrhea management[8]. This may be due to difference in educational level of mothers.

Another study showed that $<20 \%$ of mothers had favorable attitude towards preventive measures of diarrheal: like nutrition, medication, breastfeeding, proper disposal of human waste, and vaccines [9]. Similarly, in this study mothers believed that exclusive breast feeding is used as preventive and treatment factor for diarrhea. Frequent breast feeding can protect dehydration and minimize diarrheal episodes. In addition, $40.6 \%$ of mothers strongly agreed that ORS can treat and prevent dehydration, and $45.3 \%$ of mothers agreed that ORS can treat diarrhea and prevent dehydration. Contrary, study done by Papikyan et al. indicated that $46.3 \%$ of the mothers agreed that breast milk can cause diarrhea [10]. This might be due to the difference in educational level of the mothers, lack of experience in diarrhea and its management, and less prevalence of diarrheal disease in their community.

Other study explained that $73 \%$ of mothers believed that decreasing food /drink frequency at the time of diarrhea is beneficial for the child [11]. Similarly, in this study 4 mothers believed that avoiding food, fluid and decrease breast feeding are helpful to stop diarrhea. This may be due to lack of information towards impact of diarrhea, benefit of breast feeding and fluid replacement to manage diarrhea. The 
other reason may be due to low educational status of mothers.

Regarding to the cause of diarrhea, $66.6 \%$ of mothers believed that lack of personal and environmental hygiene can cause diarrhea. $2.3 \%$ of mothers believed that diarrhea can be caused by bacteria and $0.6 \%$ of mothers believed that diarrhea can be caused by virus. In line with this, a study showed that the major causes of diarrhea, as cited by the mothers, were teething $(44.3 \%)$, evil eye $(66 \%)$, eating mud $(18.6 \%)$, dirty water $(25.3 \%)$ and hot or cold foods (15\%) [9].

This study showed that $85.9 \%$ of mothers had favorable attitude towards the use of ORS to manage diarrheal. They believed that ORS is the preferable treatment of acute diarrhea, a means to prevent dehydration and correct electrolyte imbalance. This is higher as compared to studies conducted in Nigeria which indicated that $39.3 \%$ of participants believed that the use of ORT alone for the management of acute diarrhea, but only $15 \%$ did so in actual practice[12]. Contrary, the study carried out by showed that $77 \%$ of the mothers believed that only ORT was not enough as a treatment, and $23 \%$ of the mothers agreed on using ORT alone without antibiotics. While $99 \%$ of mothers agreed that there were no side effects behind its use [13]. This could be due to lack of health education and low level of maternal education.

The study conducted in Kenya revealed that almost all caregivers believed that ORS was superior to home-prepared solutions by citing a variety of reasons. One among reasons is that ORS is packaged and thus considered safer and free of contaminants, contains sugar which is necessary for homeprepared solutions though it attracts insects. They also emphasized that ORS is developed by experts and, therefore, believed to contain special therapeutic ingredients, which makes it more effective in reducing or stopping diarrhea [14]. This is comparable to the present study which accounts $85.9 \%$.

The study done by Famara Sillah et.al indicated that maternal age had no significant association with attitude of the mothers. There were no substantial difference between education and attitude, and marital status of the mother had no significant association with attitude of the mothers towards diarrhea management[15]. Similarly, this study showed that maternal age had no significant association towards diarrhea and its management.

About $67.15 \%$ of mothers believed that mixed breast feeding does not causes diarrhea. Instead, they thought that it was important for growth, development and body defense mechanism. About 51.4\% of mothers thought that supplementary feeding should be started before 6 months because breast milk was not enough for growth and development. Evidence couldn't find to comparable this study.

Single marital status, divorced and widowed had unfavorable attitude towards diarrhea management and prevention as compared to mothers who have married. This may be due to their husband's knowledge and maternal experience. However, unmarried women may not have such accesses.
Illiterate mothers and mothers who had primary educational status were strongly associated with outcome variables as compared to mothers who had university degree. The fact is that highly educated mothers have higher access of information than that of mothers who had illiterate and lower educational status.

Housewife mothers had also unfavorable attitude towards diarrhea management and prevention as compared to mothers who had governmental employee. Obviously governmental employee mothers were educated, and have opportunity to get information about benefits of breast feeding, fluids and hygiene. This can be through peer discussion, news paper, and magazine and by social media.

\section{Conclusion}

Overall, half of mothers of the Fenote Selam community had favorable attitude towards diarrhea management and prevention. Majority of mothers had favorable attitude towards exclusive breast feeding, ORS and vaccination to manage and prevent diarrhea of under five children. marital status, educational status and housewife mothers were independently associated with unfavorable attitude.

\section{Recommendation}

Health education is important to bring attitude change towards diarrhea management and prevention at home. Furthermore, awareness should be created repeatedly on benefits of home fluid management to prevent dehydration and death. The regional health bureau and zonal health department should providing training for mothers, community leaders, religious leader, health extension workers to bring attitude change diarrhea management and diarrhea prevention. Health professionals, educators, leaders, stakeholders, planners, higher officials and policy makers should be involved in diarrhea management and prevention strategies to bring attitude change through mass media by clarifying public view about the significance of nutrition during diarrheal episodes. As a result, enhanced maternal attitude would have a positive effect on diarrhea management and prevention.

\section{Acknowledgement}

Our deepest gratitude goes to Debre Markos University, Medicine and Health Sciences College for proper review and approval of this paper. We also thank Fenote Selam Town administration officials and data collectors for their cooperation and assistance.

\section{Authors' Contributions}

DA design and wrote the proposal, participated in data collection process, data analysis, interpretation and write up the manuscript. GM participated in data collection, analysis and interpretation of the data. Both authors were read and approved the manuscript. 


\section{References}

[1] Liu L, Johnson HL, Cousens S, Perin J, Scott S, Lawn JE, Rudan I, Campbell H, Cibulskis R, Li M, Mathers C, Black RE, Child Health Epidemiology Reference Group of WHO, Unicef. (2012). Global, regional, and national causes of child mortality: an updated systematic analysis for 2010 with time trends since 2000. Lancet 379:2151-2161

[2] Pickering H, Hayes R, Tomkins A, Carson D, Dunn D. (1987). Alternative measures of diarrhoeal morbidity and their association with social and environmental factors in urban children in The Gambia. Transactions of the Royal Society of Tropical Medicine and Hygiene 81:853-859

[3] Fischer Walker CL, Perin J, Aryee MJ, Boschi-Pinto C, Black RE. (2012). Diarrhea incidence in low- and middle-income countries in 1990 and 2010: a systematic review. BMC public health $12: 220$

[4] Levine MM, Kotloff KL, Nataro JP, Muhsen K. (2012). The Global Enteric Multicenter Study (GEMS): impetus, rationale, and genesis. Clinical infectious diseases : an official publication of the Infectious Diseases Society of America 55 Suppl 4:S215-224

[5] Mwambete KD, Joseph R. (2010). Knowledge and perception of mothers and caregivers on childhood diarrhoea and its management in Temeke municipality, Tanzania. Tanzania journal of health research 12:47-54

[6] Deshmukh P, Dongre A, Sinha N, Garg B. (2009). Acute childhood morbidities in rural Wardha: some epidemiological correlates and health care seeking. Indian journal of medical sciences 63:345

[7] Macro O. (2006). Central Statistical Agency Addis Ababa, Ethiopia.
[8] Usfar AA, Iswarawanti DN, Davelyna D, Dillon D. (2010). Food and personal hygiene perceptions and practices among caregivers whose children have diarrhea: a qualitative study of urban mothers in Tangerang, Indonesia. Journal of nutrition education and behavior 42:33-40

[9] Saha D, Akinsola A, Sharples K, Adeyemi MO, Antonio M, Imran S, Jasseh M, Hossain MJ, Nasrin D, Kotloff KL. (2013). Health care utilization and attitudes survey: understanding diarrheal disease in rural Gambia. The American journal of tropical medicine and hygiene 89:13-20

[10] Papikyan S. The Association of Maternal Knowledge and Management With Prevalence and Duration of Childhood Diarrheal Disease in Yerevan.

[11] Singh AK. KNOWLEDGE, ATTITUTE AND PRACTICES OF MOTHERS REGARDING ACUTE DIARRHEA MANAGEMENT IN THE URBAN POPULATION OF HILLY REGION OF UTTARAKHAND.

[12] Ogbo PU, Aina BA, Aderemi-Williams RI. (2014). Management of acute diarrhea in children by community pharmacists in Lagos, Nigeria. Pharmacy practice 12:376

[13] Al-Atrushi AM, Saeed SY, Yahya SM. (2012). KNOWLEDGE, ATTITUDE AND PRACTICE OF MOTHERS TOWARDS ORAL REHYDRATION THERAPY IN DUHOK.

[14] Blum LS, Oria PA, Olson CK, Breiman RF, Ram PK. (2011). Examining the use of oral rehydration salts and other oral rehydration therapy for childhood diarrhea in Kenya. The American journal of tropical medicine and hygiene 85:11261133

[15] Sillah F. (2012). Knowledge, Attitude and Practice Assessment of Mothers in Managing Children under Five Years Old with Diarrhea in the Gambia. 